This item was submitted to Loughborough's Research Repository by the author.

Items in Figshare are protected by copyright, with all rights reserved, unless otherwise indicated.

\title{
Water and sanitation for all in low-income countries
}

PLEASE CITE THE PUBLISHED VERSION

http://dx.doi.org/10.1680/muen.12.00018

PUBLISHER

(c) ICE Publishing Ltd.

VERSION

VoR (Version of Record)

LICENCE

CC BY-NC-ND 4.0

REPOSITORY RECORD

Jones, Hazel, Julie Fisher, and R.A. Reed. 2019. "Water and Sanitation for All in Low-income Countries". figshare. https://hdl.handle.net/2134/11742. 
This item was submitted to Loughborough's Institutional Repository (https://dspace.lboro.ac.uk/) by the author and is made available under the following Creative Commons Licence conditions.

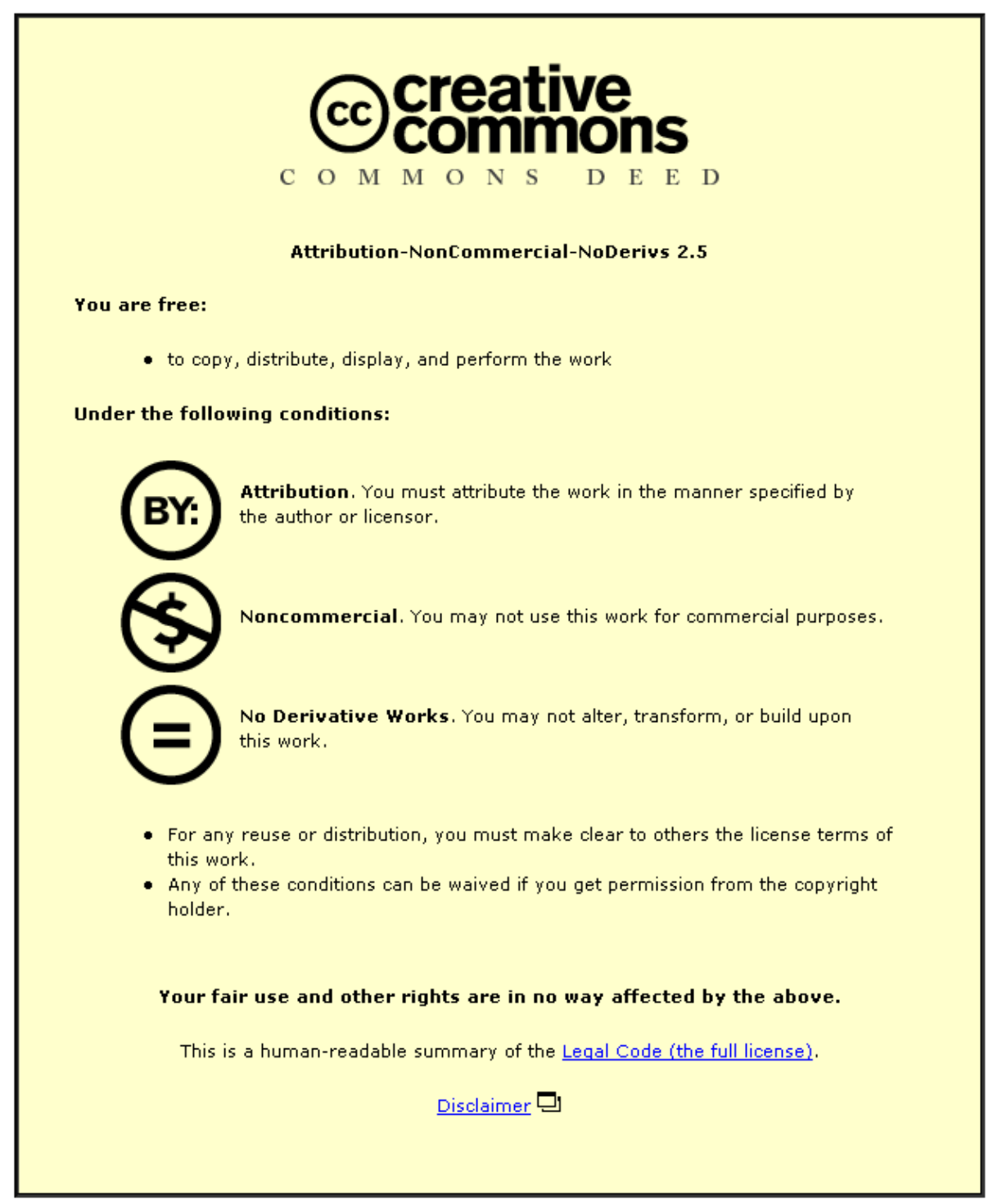

For the full text of this licence, please go to: http://creativecommons.org/licenses/by-nc-nd/2.5/ 


\section{Water and sanitation for all in low-income countries}

1 Hazel Jones MEd

Assistant Programme Manager, WEDC, School of Civil and Building Engineering, Loughborough University, Loughborough, UK

2 Julie Fisher MA, PhD

Lecturer, WEDC, School of Civil and Building Engineering, Loughborough University, Loughborough, UK
3 Robert Reed MSc, CIWEM

Senior Lecturer, WEDC, School of Civil and Building Engineering, Loughborough University, Loughborough, UK

In Europe, legislation exists to ensure that infrastructure facilities and services are accessible to all. This may not work perfectly, but there is no longer a need to debate the principle of access for all. In low-income countries it is a different story. Improving accessibility to water and sanitation is technically straightforward and low cost. Greater challenges are posed by institutional and social barriers. However, evidence shows that increased advocacy and information, together with training of engineers about inclusive design, can reduce prejudice and increase understanding of different needs and solutions. Drawing on examples from Africa and Asia, this paper describes water and sanitation in low-income countries, explaining the barriers that prevent access for vulnerable users and gives an overview of inclusive design for latrines and water points.

\section{Introduction}

In the UK and Europe, accessibility and inclusive design of public infrastructure is increasingly becoming the norm. Inclusive design is about making places that everyone can use. The way places are designed affects our ability to move, see, hear and communicate effectively. Inclusive design aims to remove the barriers that create undue effort and separation. It enables everyone to participate equally, confidently and independently in everyday activities. As defined by the Centre for Accessible Environments (http://www.cae.org.uk/inclusive.html), inclusive design

\footnotetext{
places people at the heart of the design process

responds to human diversity and difference

- offers dignity, autonomy and choice

v provides for flexibility in use.
}

This means that design processes result in products or environments that can be accessed and used by everyone, regardless of age, gender, disability, race, income, education and culture (Shipley, 2002). These are issues that, to a greater or lesser extent, touch all our lives at different times and inclusion should not therefore be seen as applying only to a minority of people. Legislation, guidelines and enforcement procedures aim to ensure that these principles are adhered to and it is no longer necessary to debate the pros and cons of 'access for all'.

In most low- and middle-income countries however, it is a different story. Despite data from 36 countries in Asia and the Pacific showing that $72 \%$ have accessibility standards for either the built environment or public transport or both, awareness of them among engineers is often low (Who and World Bank, 2011). Where standards are known, there is often concern 'about their appropriateness, especially for resource-poor settings, including rural areas... and informal settlements' (Who and World Bank, 2011).

In relation to the provision of water, sanitation and hygiene (Wash) in low-income countries, accessibility for vulnerable members of the community is not a high priority where general services are inadequate. This leaves millions of the poorest and most disadvantaged with inadequate water and without access to even the most basic toilet.

Evidence shows that working towards ensuring equity through the principles of accessibility and inclusive design has significant impacts on the health and welfare of all individuals. This paper will outline what the main problems are and how they can be addressed in order to make a difference, with supporting examples of the types of outcomes that can be achieved.

\subsection{Water and sanitation provision in low-income countries}

Latest assessments by the Joint Monitoring Programme (JMP) estimate that 780 million people globally have no access to an 'improved' source of drinking water and $2 \cdot 5$ billion people have no access to 'improved sanitation'. Unicef/Who (2012) define these terms as follows.

An improved drinking water source adequately protects the source from outside contamination, in particular from faecal matter. 
- An improved sanitation facility hygienically separates human excreta from human contact.

As the JMP points out, these figures mask important disparities in the distribution of water and sanitation. When wealth quintiles are applied, it becomes clear that the poorest have the least access. For example, in sub-Saharan Africa, 90\% of the richest population quintile living in urban areas use improved water sources and sanitation, and most have a piped water supply. In comparison, none of the poorest rural quintile has piped water and $60 \%$ practice open defecation. Similarly, in Southern Asia, $80 \%$ of people in the two poorest quintiles practice open defecation (Unicef/Who, 2012).

Assessments also show that time and effort spent collecting water can be significant, the responsibility for which mainly lies with women and girls. In the 25 sub-Saharan countries assessed, the mean time of one round-trip to collect water for a household is approximately $30 \mathrm{~min}$ - a journey carried out at least once a day (Unicef/Who, 2012).

\subsection{Access and use of facilities by vulnerable people}

A number of disadvantaged groups are disproportionately poor, placing them immediately at risk of inadequate access to Wash facilities. Disabled people are more likely to be poor than the general population (Jones and Reed, 2005) and 600 million people aged over 60 lack income security, the majority of these being women (OHCHR, 2012). Over 1 billion people globally are disabled (Who and World Bank, 2011), more than 1 in 5 people in developing countries will be over 60 by 2050 (http:// www.helpage.org/resources/ageing-data) and more than 33 million people are living with HIV (UNAids, 2010).

These are groups who, in addition to issues of poverty, may find it difficult or impossible to reach and use existing water and sanitation facilities. The inaccessibility of and long distances to water sources, long waiting times and the need to carry heavy loads mean that those who are not fit and well might find it difficult or impossible to carry out these tasks. Sanitation facilities may also be at a distance and may not be designed or built to take into account the needs of different vulnerable people. The groups routinely affected include children and adults with disabilities, frail older men and women, young children, women and adolescent girls, especially when heavily pregnant or when menstruating, and people with chronic illnesses, including people living with HIV (PLWHIV).

Improving access for these disadvantaged groups is important not only for the health and wellbeing of individuals, but for a range of wider benefits to families and the community as a whole, including education, poverty reduction, economics and human rights, as follows.
- Health. Unhygienic sanitation practices by disabled people, older people and PLWHIV not only affect their own health, but the health of the whole community.

Education. Disabled children and adolescent girls often drop out of school or are refused admission due to lack of adequate and accessible sanitation.

- Poverty reduction. Inclusive facilities reduce dependence on caregivers, thereby reducing the workload of the family and increasing the time available for other activities such as education, employment and recreation.

Economics. The cost of making facilities inclusive is minimal compared with the costs of exclusion.

- Rights. Water and sanitation are a human right for all, not just for some.

- Gender. Disability and HIV/Aids are gender issues; caregivers are usually female; women do most fetching of water and caring for sick or dependent relatives.

Over the last 20 years, Wash service providers have begun to pay attention to the needs of disadvantaged groups. The predominant focus has been on women, with efforts to mainstream gender issues making the greatest inroads into Wash programming (Fisher, 2008). Issues relating to different stages of women's lives, such as harassment of adolescent girls, menstrual hygiene management, pregnancy/motherhood and ageing are recognised as important factors to consider in service provision. Engineers have also recognised that women can contribute to the design of facilities, for example floors that are easy to clean (Reed et al., 2007) and provision for menstrual hygiene management (Crofts and Fisher, 2012).

The issue of child-friendly taps and toilets has also received attention, particularly in relation to school sanitation, including child-sized toilet holes and seats and the use of colour and images for younger children (Zomerplaag and Mooijman, 2005). Solutions to make latrines user-friendly for adolescent girls include constructing separate boys' and girls' blocks to ensure privacy (Reed et al., 2008) and providing facilities for washing and/or disposal of sanitary materials (IRC, 2006).

The issue of user-friendly design for disabled people, older people and PLWHIV has only received attention in the last decade. Some information has been produced on simple lowcost solutions and approaches to help service providers make Wash services and facilities more accessible for disabled people (Jones and Reed, 2005; Norman, 2010). An increasing number of international organisations working in the Wash sector are now also engaging with these issues.

Given this relatively recent research activity addressing the needs of different groups, what is the state of knowledge and understanding of both the existing barriers and the possible solutions to access and inclusion to Wash services? 


\section{Barriers to access and inclusion}

A number of studies in Africa and Asia have identified a range of barriers preventing access to Wash facilities for disabled children and adults (Drafor and Jones, 2008; Jones and Reed, 2005; Tesfu and Magrath, 2008), women and girls (Fisher, 2006; WSSCC, 2004), older men and women (Sleap, 2006) and PLWHIV (Potgieter et al., 2007; Tesfu and Magrath, 2008). These barriers are categorised in Table 1 .

\subsection{Physical barriers}

In the natural and built environment, physical barriers are the easiest to identify. Many disabled or frail older people are unable to walk long distances to a water point, stand in a queue for long periods, operate the heavy handle of a handpump or carry a 201 container of water back home (Jones et al., 2003). Access to water sources such as ponds and wells can also be slippery and hazardous. This may result in reliance on other family members to fetch water or to resorting to unsafe but closer water sources. This particularly impacts disabled and older women whose domestic role and sense of self-worth are linked to managing water for the household (Norman, 2010).

People with chronic illnesses, including HIV, for whom good hygiene is crucial, are likely to find their access to clean water reduced. One study showed that PLWHIV in rural South Africa were forced to walk long distances to collect untreated
Physical: natural environment and built infrastructure

Institutional/ organisational

\section{Social/cultural/ attitudinal}

- Long distances, rough or steep paths, muddy ground

High steps, narrow entrances, no doors, slippery or dirty floors, narrow cubicles, no light, heavy pump handles

- Inappropriate locations - risk of insecurity, lack of privacy

- Lack of equality legislation or policies

- Non-implementation of laws

No minimum standards

- No inclusive designs

- No training of engineers

- Lack of information

- No procedures for consultation with disabled people

- Lack of information

- Traditional beliefs

Pity

Isolation

- Overprotection

- Stigma

Prejudice

- Shame
Table 1. Examples of barriers to access and inclusion water, carrying 20-25 1 water containers when they were already weak. These factors, added to their health issues, often left families with insufficient water, further impacting on the wider household (Potgieter et al., 2007).

Those with limited mobility such as pregnant women and disabled, sick or older people may find it impossible to squat in a latrine with nothing to hold onto. They often resort to sitting or putting their hands on the dirty floor for balance (Figure 1), which exposes them to increased risk of infection (Jones et al., 2003; Norman, 2010; Tesfu and Magrath, 2008). Toilet cubicles are frequently too small, making it difficult for caregivers to assist.

\subsection{Institutional barriers}

Institutional barriers are less immediately obvious and often harder to change. Existing legislation and policies on disability can lack strategies or guidelines for implementation. Where they exist, accessibility laws and standards in low-income countries have largely been driven by standards in industrialised countries, rather than reflecting local cultural or economic conditions, which may account for their lack of implementation (Who and World Bank, 2011). Often, the relevant ministries responsible for water or sanitation are completely unaware of national disability legislation.

There is a lack of knowledge and skills about accessible and inclusive design among Wash personnel in low-income countries, mainly because this is not part of the training of engineers (Reed and Coates, 2003) and because they are unlikely to have seen real examples of inclusive design. The majority of engineers are male and traditionally design and construct facilities for the 'average' person, with no user consultation and without considering that, in real communities, people come in a wide range of shapes, sizes and ages and with a wide variety of needs (Jones and Reed, 2005).

There is also a lack of information for families. Where latrine construction is the household responsibility, they tend to copy latrines they have seen, unaware of alternative technologies that make toilets easier to use, such as seats or handrails (Jones and Reed, 2005).

\subsection{Social and attitudinal barriers}

The most insidious barriers are social and attitudinal. Negative attitudes and stigma attached to certain minority groups, combined with misinformation about issues of disability and illness, result in disabled people in particular being ostracised and hidden, thereby perpetuating the low priority and lack of attention paid to exclusion.

For example, in Madagascar, disability is seen as a punishment from God or ancestors for past sin. Disabled people are considered useless, excluded from community decision-making and have no opportunities to express their needs (WaterAid Madagascar, 2010a). A study in rural Mali found that families' 
Water and sanitation for all in

low-income countries

Jones, Fisher and Reed

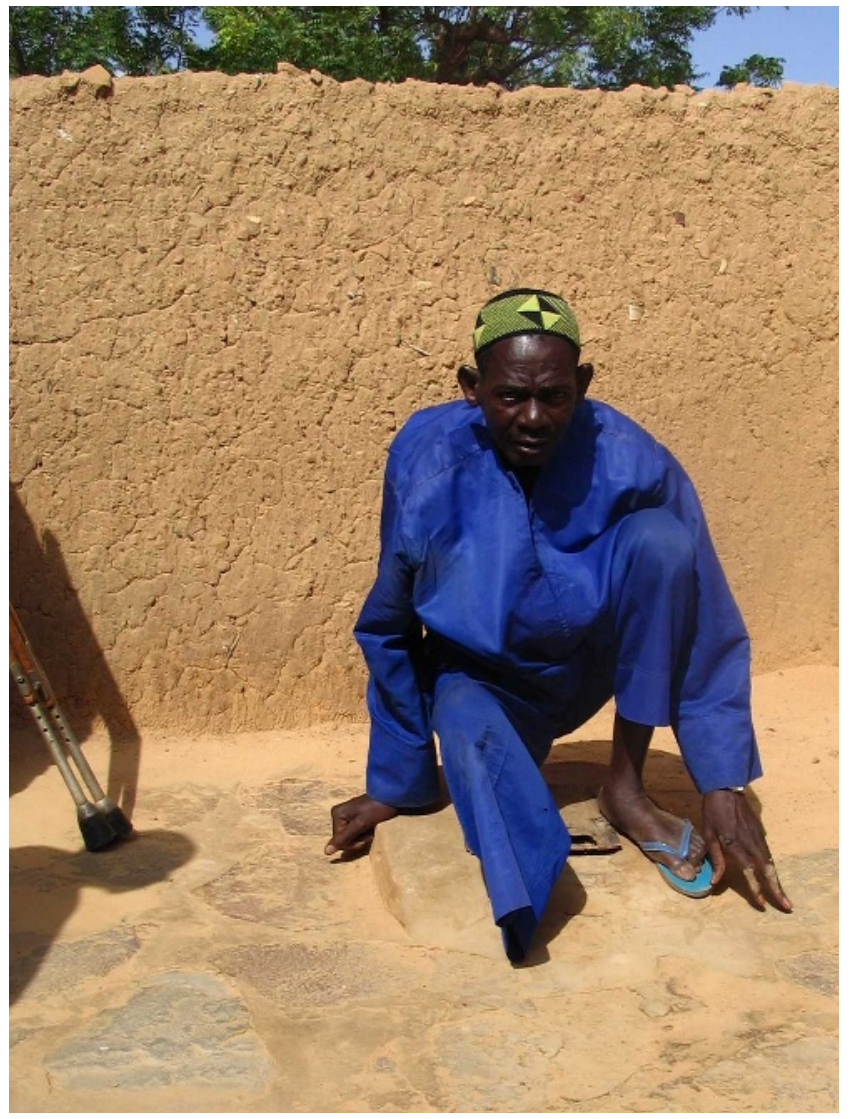

Figure 1. Demonstration of how a disabled person might squat on a latrine using hands for support

attitudes towards disabled women focused on their 'inability' and 'risk of personal injury' when it came to fetching water, although the women felt they were capable of deciding this for themselves (Norman, 2010).

\section{Dismantling barriers}

An increasing number of organisations are implementing initiatives to address some of these issues. The majority of examples used to illustrate this section relate to disabled people, since facilities that are accessible and usable by disabled people are invariably accessible for other disadvantaged groups such as pregnant women, older people and those with chronic illness.

\subsection{Addressing physical barriers}

Many of the changes required to make physical infrastructure and facilities more accessible and user-friendly are straightforward. For example, the following types of changes benefit disabled people: reducing the distance to facilities; removing obstacles from paths; levelling and grading paths; installing ramps instead of steps; reducing the height of steps; widening doors; installing handrails and/or a seat for support (Figures 2 and 3). These can be beneficial at home (Jones and Reed, 2005; WaterAid Mali, 2007) or at school (Jones, 2011). All of these solutions were also found to benefit older people and PLWHIV, especially reducing the distance to facilities (Sleap, 2006; USAID/HIP, 2011). For women in Tibet, the use of a 'back happy' tapstand, allowing them to fill and lift water jars without bending (Figure 4), is a simple means of improving quality of life (Hoy et al., 2003).

\subsubsection{Implementing technical solutions}

The usual reaction of engineers working in low-income countries is that it would be impossible and too expensive to incorporate each solution to meet every different need. So the question for Wash service providers is: how can these solutions be incorporated into regular Wash service delivery? The broad approaches to reducing physical barriers are considered here, based on Jones and Jansz (2008).

- Individual approach. This starts with an assessment of the problems and needs of a particular category of individual users (e.g. disabled people) and the provision of aids, equipment or adaptations based on this assessment. The advantage of this approach is that solutions are tailored to meet the needs of individuals so they are likely to be effective. The disadvantage is that this often requires a one-to-one assessment, which is labour intensive and time consuming. If a separate 'special' facility is provided, this becomes high cost and increases the risk of further isolating users.

- Adaptation and retrofitting. This approach involves modifying or adding to existing facilities, for example adding a handrail or seat to an existing latrine or a ramp to provide access to an existing water point. The advantage of this approach is that it provides access to the same facility used by others and it can be done as and when it is needed when a disabled child is about to enrol in primary school for example. On the other hand, adaptation can be difficult

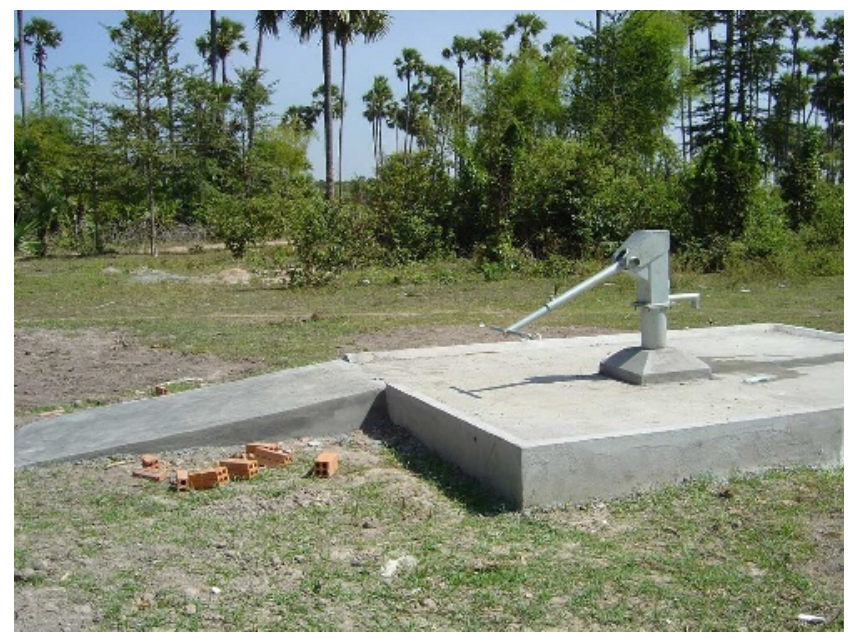

Figure 2. Handpump platform with ramp in Cambodia 
Water and sanitation for all in

low-income countries

Jones, Fisher and Reed

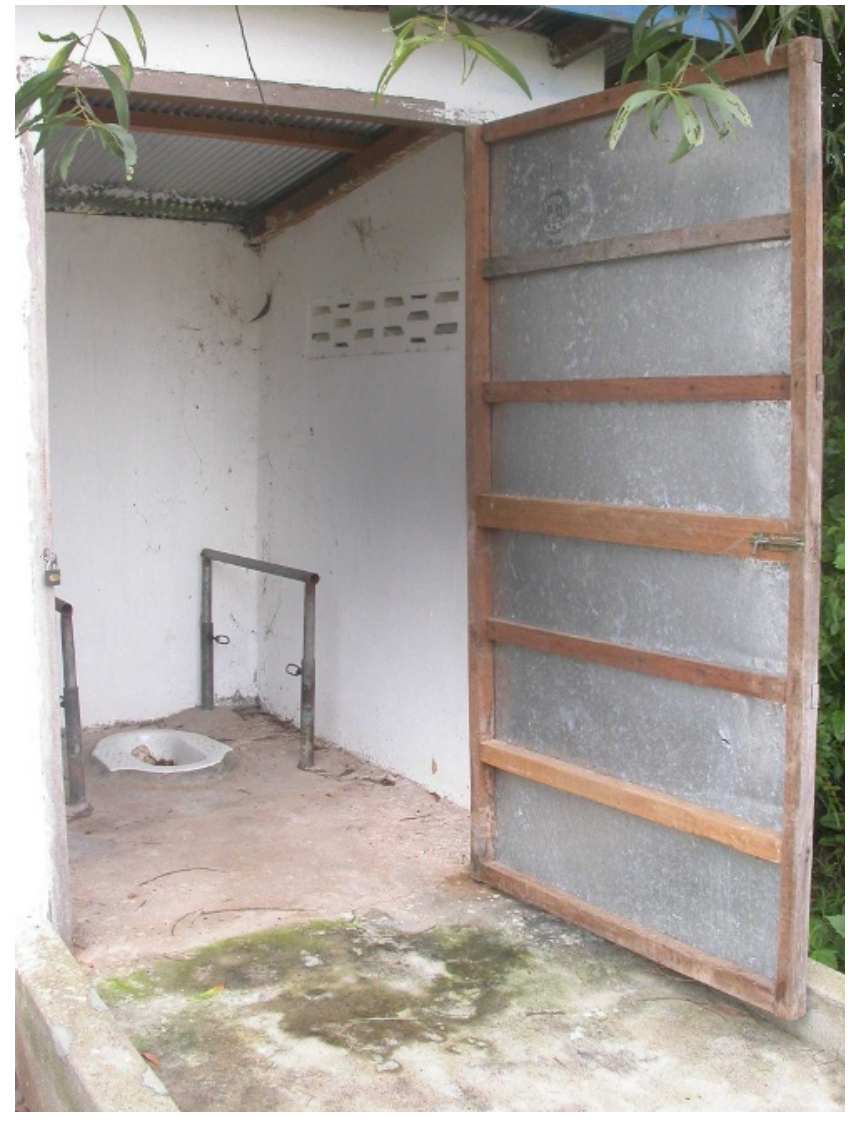

Figure 3. Latrine with handrails and wide door

with some structures; for example where there are very high steps or where a cubicle or door needs to be widened the cost becomes prohibitively high.

- Inclusive approach. This starts with identifying problems with existing facilities and services that make it difficult for users, whoever they may be, to comfortably access and use them. This is done by consulting users to define their needs and to help design and implement solutions. This process is known as inclusive design - the design and construction of facilities that are accessible and easy for all to use, as noted in Section 1. This approach is cost-effective when planned from the outset, but consultation processes can be slow. Although inclusive design aims to maximise inclusion, it is highly unlikely that a single design will meet the needs of every user.

\subsubsection{Household facilities}

At the household level there are a limited number of users, most of whom are known and whose current needs can be identified and near-future needs largely foreseen (e.g. ageing, pregnancy, illness). This scenario requires a basic user-friendly design and a range of accessibility features to choose from. The basic design should provide adequate floor space and minimum entrance width - these features benefit everyone and are

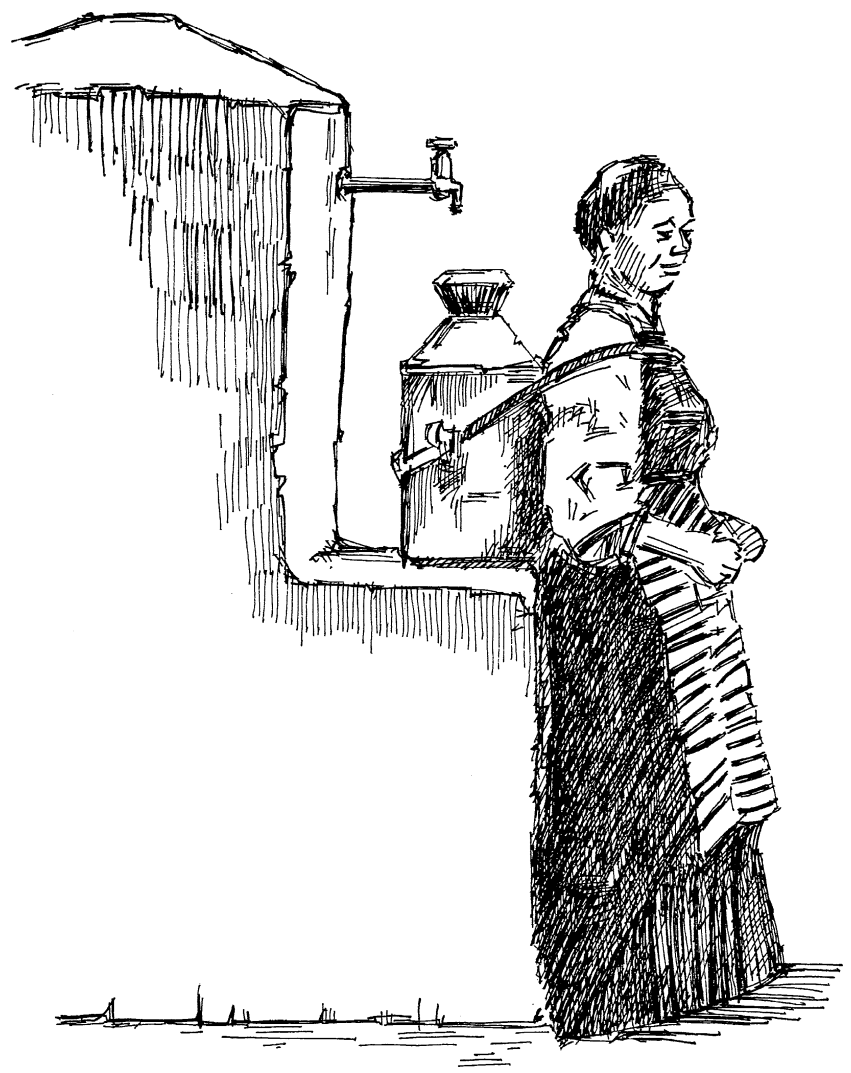

Figure 4. 'Back happy' tapstand in Tibet

the most difficult and costly to modify post-construction. Seats, handrails and ramps are easier to add later; they can be constructed with low-cost materials initially to test their benefits and upgraded at a later date as the needs of the family change and household resources permit.

An example of this approach has been implemented by WaterAid in Nepal, in the form of a pilot project to provide latrine adaptations for disabled people in 50 rural households. For the $50 \%$ of families with an existing latrine, simple, locally made moveable toilet seats were provided. These seats can be placed over the squat pan of a latrine to reduce the need for the disabled person to crawl on a dirty toilet floor or sit on the toilet slab (Shrestha, 2006).

\subsubsection{Communal/institutional facilities}

These include latrines or water points designed for use by the general public (e.g. at a market) or by users of an institution (e.g. a school) or by a group of neighbouring households. In such situations there are a large number of users, many unknown, with a wide range of possible current and future needs. This scenario requires an inclusive design approach.

In Mali, WaterAid was requested by Sightsavers, a disability organisation, to rehabilitate a communal well in a village with a 
high number of blind inhabitants. The existing wells with low walls were unsafe for blind users. Following a consultation process with disabled people, a well was designed that was accessible and safe for all to use. The resulting design has a high wall to provide protection against falling, physical support when lifting water and one section of wall has been lowered for use by children or wheelchair users. A concrete ramp provides access for wheelchair users (WaterAid Mali, 2007).

A key message for engineers is that, on the whole, the technology itself does not need to change - it is the way it is installed that has most impact on users.

\subsection{Addressing institutional barriers}

The majority of effort to date has been directed at improving the accessibility of infrastructure, but it has become apparent that - for improvements to be effective and sustainable - a range of institutional and social barriers to do with how facilities and services are delivered also needs to be addressed.

\subsubsection{Information provision}

Information for households. For latrines that are the responsibility of the household, it is unrealistic to expect Wash service providers to provide individually tailored solutions. What is needed, however, is information to help families make informed choices. There is now an increasing body of basic information on low-cost accessibility options, using drawings and photos of solutions that have been found to work locally, aimed at households in rural areas (e.g. WaterAid Bangladesh, 2009) and at families with a person with HIV (USAid/HIP, 2011).

- Information for decision-makers. Individual field workers and practitioners have only limited say on infrastructure designs. Key decision-makers in relevant ministries need to be persuaded, for which advocacy materials are required that need to be brief, eye catching and contain key messages, including poverty reduction and cost-effectiveness, practical examples and colour photos. For example, a briefing note was produced for this purpose (Fisher and Jones, 2005), based on the research by Jones and Reed (2005), which has since prompted local versions, for example in East Africa (Rukunga et al., 2006) and Timor Leste (WaterAid Australia, 2011).

- Information about cost-benefits. Some limited studies have been carried out on the additional cost of making facilities inclusive (e.g. WaterAid Madagascar, 2010b) and on the costs of accessible school sanitation in Ethiopia (Jones, 2011), but further research is needed.

\subsubsection{Capacity development}

The lack of knowledge and skills of engineers and technicians in low-income countries about accessibility and inclusive design is a major weakness. Information giving examples of good practice, the construction of demonstration facilities and lobbying by disabled people themselves can all make a difference. In the long term, however, what is needed is for inclusive design to be included on the curriculum of engineering and architecture courses in African and Asian countries.

On the other hand, having emphasised the importance of disabled people's participation in developing standards, it is important that disabled people's representatives need training to avoid their participation becoming 'tokenism'.

Accessibility audits have been used to great effect in capacity building. These are increasingly used in the UK to examine the accessibility of a service or facility, identify barriers, assess usability and provide options for improvement (www.inclusion.me.uk). They work best when engineers and disabled people are brought together to work as a team. The practical nature of the activity provides a structure for disabled people to use their experience for proposing and developing solutions (Figure 5). It also gives disabled people an understanding of the kind of information engineers need to inform and improve designs of facilities.

\subsubsection{Development of inclusive design standards}

In many countries, there are nationally agreed designs for public infrastructure, such as latrines and water points in schools and health clinics. In the long term, a systematic approach to the development of minimum standards for inclusive designs is needed. We know that 'technical standards [are] established by consensus emerging from participation of all interested persons or institutions' (Alvarez, 2000). This indicates that a process of partnership development and consultation is needed, with

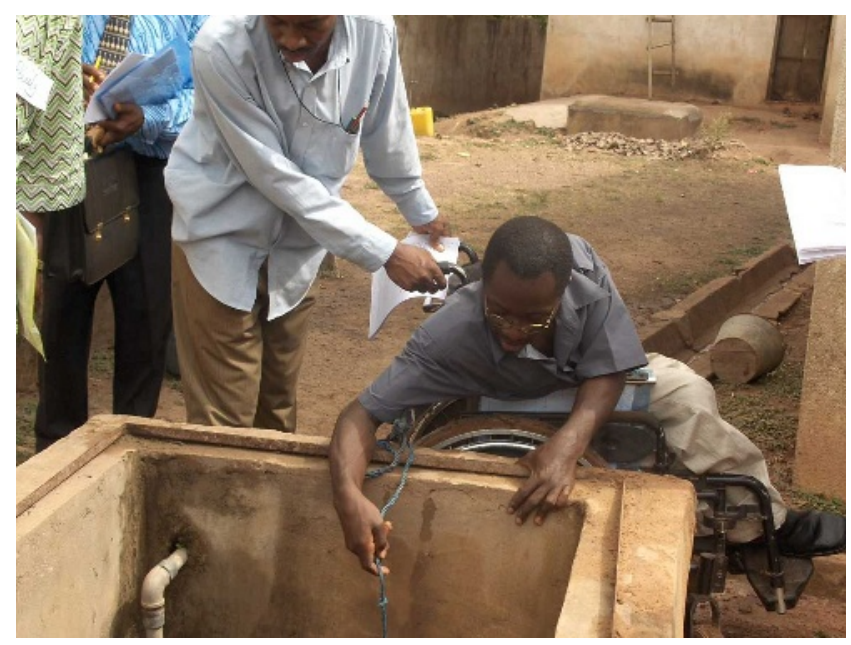

Figure 5. Audit team evaluating accessibility of a well 
a participation of disabled people in developing standards

- laws with mandatory access standards

mechanisms to enforce compliance and penalties for noncompliance (Who and World Bank, 2011).

On a local scale, a good example of participation of disabled people in developing an inclusive design is from Madagascar, where WaterAid constructed a public latrine and water point according to accessibility guidelines. For example, steps to a water point were replaced by a ramp, traditional taps replaced with lever taps and handrails were installed in the latrine cubicle. WaterAid then invited a local disabled people's organisation to carry out an accessibility audit of the facilities. The auditors identified a number of obstacles still remaining, including a ramp too steep for a wheelchair user, lack of a level platform to rest while opening the door, lack of physical landmarks or signposting for orientation of blind users and a water point installed centrally in the concrete slab, leaving insufficient turning space. The designs were re-drafted and further facilities constructed based on the findings of the audit (WaterAid Madagascar, 2010b, 2011).

\subsection{Addressing social/attitudinal barriers}

Negative attitudes can be effectively addressed not as a separate issue but incorporated into practical implementation. Seeing disadvantaged people not only as beneficiaries but as active participants in their own development can be pivotal to changing attitudes, both of the community and of disabled people themselves.

Using accessibility audits as described above, engineers lose their anxiety about how to communicate with disabled people and realise that they have experience and information to contribute. At the same time, the experience of being listened to and contributing to problem-solving can also be an empowering one for disabled people that increases confidence and self-esteem.

\section{Conclusion}

This paper shows that a large number of people are not benefiting from water and sanitation provision, many of whom are among the most disadvantaged in the community. However, most people at some point in their lives (e.g. through ageing, pregnancy or illness) can benefit from accessible and inclusive design. Making improvements to suit the needs of one group also invariably increases access for other groups, so the benefits are multiplied.

It has been demonstrated that there are strong reasons for improving access, not only in terms of the social benefits offered but also because it can make a positive contribution to poverty alleviation and economic development. Technically, it is not difficult to improve accessibility - the solutions are relatively simple and low cost. The more difficult challenges are posed by institutional and social barriers to Wash provision.

However, evidence shows that increased advocacy and information provision for all levels - from household members to policy makers - together with training of engineers and technicians on design and construction will help to reduce prejudice, increase awareness of the different needs and solutions, and therefore raise demand for improved services that are accessible to all.

\section{REFERENCES}

Alvarez E (2000) Pathways to Accessibility: Disability and the Physical Environment in Latin America and the Caribbean. Inter-American Development Bank, Washington, DC, USA, Sustainable Development Department Working Paper.

Crofts T and Fisher J (2012) Menstrual hygiene in Ugandan schools: an investigation of low-cost sanitary pads. Journal of Water, Sanitation and Hygiene for Development 2(1): 50-58.

Drafor I and Jones H (2008) Access to water and sanitation in Ghana for persons with disabilities: findings of a KAP survey. Proceedings of 33rd WEDC International Conference, Accra, Ghana. WEDC, Loughborough University, UK, pp. 36-40.

Fisher J (2006) For Her It's the Big Issue. Putting Women at the Centre of Water Supply, Sanitation and Hygiene. Water Supply and Sanitation Collaborative Council (WSSCC), UNICEF, WEDC. See http://www.wsscc.org/sites/default/ files/publications/wsscc_for_her_its_the_big_issue_ evidence_report_2006_en.pdf (accessed 30/05/2012).

Fisher J (2008) Women in water supply, sanitation and hygiene programmes. Proceedings of the Institute of Civil Engineers - Municipal Engineer 161(4): 223-229.

Fisher J and Jones HE (2005) Why Should the Water and Sanitation Sector Consider Disabled People? WEDC, Loughborough University, UK, WELL briefing note 12 .

Hoy D, Toole MJ, Morgan D and Morgan C (2003) Low back pain in rural Tibet. The Lancet 61(9353): 225-226.

IRC (2006) Ghana-Girl-friendly Toilets for Schoolgirls: Helping Adolescent Girls. IRC International Water and Sanitation Centre. See http://www.schools.watsan.net/page/ 319\%20\%5b2009 (accessed 30/05/2012).

Jones HE (2011) Inclusive Design of School Latrines - How Much Does it Cost and Who Benefits? WEDC, Loughborough University, UK, Briefing note 1.

Jones HE and Jansz S (2008) Disability and Sanitation. WaterAid, London, UK, Briefing note 3.

Jones HE and Reed RA (2005) Water and Sanitation for Disabled People and Other Vulnerable Groups: Designing Services to Improve Accessibility. WEDC, Loughborough University, UK.

Jones HE, Reed RA and Bevan JE (2003) Water and sanitation for the disabled in low-income countries. Proceedings of the Institute of Civil Engineers - Municipal Engineer 156(2): 135-141.

Norman RW (2010) Water, Sanitation and Disability in Rural West Africa: Enhancing Access and Use of WASH facilities. Summary report of the Mali water and disabilities study. Messiah College, USA. See http://www.wsscc.org/sites/ default/files/publications/norman_washdisabilities_ ruralafrica_2010.pdf (accessed 30/05/2012). 
OHCHR (2012) Older Persons Among the Poorest in the World. United Nations Office of the High Commissioner for Human Rights. See http://www.ohchr.org/EN/NewsEvents/ Pages/Olderpersonsamongthepoorestintheworld.aspx (accessed 30/05/2012).

Potgieter N, Koekemoer R and Jagals P (2007) A pilot assessment of water, sanitation, hygiene and home-based care services for people living with HIV/AIDS in rural and peri-urban communities in South Africa. Water Science and Technology 56(5): 125-131.

Reed BJ and Coates S (2003) Engineering and gender issues - evidence from low-income countries. Proceedings of the Institution of Civil Engineers - Municipal Engineer 156(2): 127-133.

Reed BJ, Coates S and Parry-Jones S et al. (2007) Infrastructure for All: Meeting the Needs of Both Men and Women in Development Projects. A Practical Guide for Engineers, Technicians and Project Managers. WEDC, Loughborough University, UK.

Reed R, Shaw R and Chatterton K (2008) Sanitation for Primary Schools in Africa. WEDC, Loughborough University, UK.

Rukunga G, Mutethia D and Kioko T (2006) Why the Water and Sanitation Sector in East Africa Should Consider Disabled People. WEDC, Loughborough University, UK, WELL country note 12.1 .

Shipley A (2002) What is Inclusive Design and How Can it Achieve a Built Environment to be Enjoyed by Everyone? Discussion Report, Disability Rights Commissions Round Table Discussion on Inclusive Design, London, UK.

Shrestha GR (2006) Case Study on Addressing Sanitation Needs of Disabled People in Nepal. Final Draft - 1. Nepal Water for Health (NEWAH), Kathmandu, Nepal. See http:// www.asksource.info/pdf/35891_CSsanitationDPOs Nepal_2006.pdf (accessed 30/05/2012).

Sleap B (2006) Access for all: securing older people's access to water and sanitation. Proceedings of 32nd WEDC International Conference, Colombo, Sri Lanka. WEDC, Loughborough University, UK, pp. 369-372.

Tesfu M and Magrath P (2008) Equal access for all? Issues for people with HIV and with disabilities in Ethiopia. Proceedings of 33rd WEDC International Conference, Accra, Ghana. WEDC, Loughborough University, UK, pp. 133-140.

UNAIDS (2010) Annual Report 2009. Joint United Nations Programme on HIV/AIDS. See http://data.unaids.org/pub/Report/ 2010/2009_annual_report_en.pdf (accessed 30/05/2012).

UNICEF/WHO (2012) Progress on Sanitation and Drinking Water: 2012 Update. WHO/UNICEF Joint Monitoring Programme for Water Supply and Sanitation. See http:// www.wssinfo.org/fileadmin/user_upload/resources/JMPreport-2012-en.pdf (accessed 30/05/2012).

USAID/HIP (2011) Integrating Sanitation into the Basic Care Package. USAID and Hygiene Improvement Programme, Washington, DC, USA. See http://www.inclusivewash.org. au/hiv-aids-chronic-illness (accessed 30/05/2012).
WaterAid Australia (2011) How the WASH Sector in Timor-Leste can Consider People with Disabilities. WaterAid, Timor Leste. See http://www.inclusivewash.org.au/_literature_69010/ How_the_WASH_sector_can_consider_people_with_ disabilities_in_Timor-Leste (accessed 30/05/2012).

WaterAid Bangladesh (2009) Technical Guideline for Latrine of Differently Abled People. WaterAid, Bangladesh.

WaterAid Madagascar (2010a) Etat de l'Inclusion et de l'Equité à Madagascar. WaterAid, Madagascar.

WaterAid Madagascar (2010b) Technical Manual on Community Water Supply, Sanitation and Hygiene Facilities. WaterAid, Madagascar. See http://www.wateraid.org/documents/ plugin_documents/brochure_a5_wateraid_anglais_nov_ bas.pdf (accessed 30/05/2012).

WaterAid Madagascar (2011) Diagnosing Accessibility. See http:// www.youtube.com/watch? $\mathrm{v}=\mathrm{DEAYh} 5 \mathrm{nezSQ}$ (accessed 30/ 05/2012).

WaterAid Mali (2007) All People, One Goal, All Access: Water and Sanitation Access for People with Disabilities. WaterAid, Mali. See http://www.wateraid.org/documents/ plugin_documents/all_people_one_goal_all_access.pdf (accessed 30/05/2012).

WHO and World Bank (2011) World Report on Disability. World Health Organization, Geneva. See http://www.who.int/ disabilities/world_report/2011/en/index.html (accessed 30/ 05/2012)

WSSCC (2004) WASH Advocacy Materials. Water Supply and Sanitation Collaborative Council, Geneva. See http://www. wsscc.org/wash-advocacy/wash-advocacy-materials (accessed 30/05/2012).

Zomerplaag J and Mooijman A (2005) Child-Friendly Hygiene and Sanitation Facilities in Schools: Indispensible to effective hygiene education. IRC International Water \& Sanitation Centre; UNICEF, The Netherlands. http://www.washdoc. info/docsearch/title/112771 (accessed 30/05/2012).

\section{WHAT DO YOU THINK?}

To discuss this paper, please email up to 500 words to the editor at journals@ice.org.uk. Your contribution will be forwarded to the author(s) for a reply and, if considered appropriate by the editorial panel, will be published as discussion in a future issue of the journal.

Proceedings journals rely entirely on contributions sent in by civil engineering professionals, academics and students. Papers should be 2000-5000 words long (briefing papers should be 1000-2000 words long), with adequate illustrations and references. You can submit your paper online via www.icevirtuallibrary.com/content/journals, where you will also find detailed author guidelines. 